\title{
Exploitation of rocky intertidal grazers: population status and potential impacts on community structure and functioning
}

\author{
Gustavo M. Martins ${ }^{1,2,3, *}$, Stuart R. Jenkins ${ }^{3,4}$, Stephen J. Hawkins ${ }^{3,5}$, Ana I. Neto ${ }^{2}$, \\ Richard C. Thompson ${ }^{1}$

\begin{abstract}
${ }^{1}$ Marine Biology and Ecology Research Centre, Marine Institute, University of Plymouth, Plymouth PL4 8AA, UK ${ }^{2}$ Secção Biologia Marinha and CIRN, Departamento Biologia, Universidade dos Açores, 9501-801 Ponta Delgada, Açores, Portugal ${ }^{3}$ Marine Biological Association, Citadel Hill, Plymouth PL1 2PB, UK ${ }^{4}$ School of Ocean Sciences, University of Wales Bangor, Menai Bridge, Anglesey LL59 5EY, UK ${ }^{5}$ College of Natural Sciences, University of Bangor, Bangor, Gwynedd LL57 2UW, UK
\end{abstract}

\begin{abstract}
A wide range of anthropogenic activities are impacting the ecology of coastal areas. Exploitation of marine resources is one such activity, which, through cascading trophic effects, can have influences well beyond that of the target species. We investigated the mid-rocky-shore community structure of the Azores archipelago, a seldom-studied habitat, where there is a local tradition of exploiting limpets, the main intertidal grazers. The limpet population structure differed among islands, and there was an inverse relationship between the abundance of larger limpets and the human population per coastal perimeter, but not the associated catch data. At small scales of resolution (quadrats), there was a negative relationship between the cover of algae and limpets and a positive relationship between barnacles and limpets. These relationships were also apparent at the larger scale of islands as a function of the gradient of exploitation. Our results show how natural habitat fragmentation may be useful where the experimental testing of a hypothesis is not possible, and provide evidence for the trophic cascading effects of limpet exploitation at landscape scales.
\end{abstract}

KEY WORDS: Harvesting · Exploitation index · Patella candei · Patella aspera Population structure · Community structure $\cdot$ Fragmented habitats $\cdot$ Islands

\section{INTRODUCTION}

The rocky intertidal is a highly productive system supporting diverse assemblages of plants and animals. However, its accessibility to humans has rendered it susceptible to a variety of anthropogenic impacts (Thompson et al. 2002). Human populations have a long tradition of exploiting intertidal resources, and concern about the effects of this disturbance have prompted much research, for example in Chile and South Africa (see Siegfried 1994 for review). At these localities, exploitation was shown to cause a reduction in the abundance and mean size of exploited species (e.g. Branch 1975, Castilla \& Durán 1985). In addition, there is increasing evidence that the effects of fishing can extend well beyond the exploited species through cascading trophic effects (Castilla 1999, Scheffer et al. 2005) that can change community structure and the functioning of ecosystems at landscape scales of resolution (Durán \& Castilla 1989, Lindberg et al. 1998, Castilla 1999).

The majority of rocky intertidal benthic invertebrates have complex life cycles that include planktonic and bottom-dwelling phases, linked by a settlement event (Thorson 1950). Larvae released by benthic adults into the water column are dispersed by physical 
transport (Morgan 2001) in such a way that, in open systems (e.g. islands, headlands), local production can have little impact on local recruitment (Caley et al. 1996). The replenishment of benthic populations is largely dependent on the supply of new individuals, which is a function of the abundance of planktonic larvae, the behaviour and physical processes bringing larvae into contact with the substratum, and the availability of suitable sites for settlement (Minchinton \& Scheibling 1993). Anecdotal evidence suggests that fragmented habitats such as islands typically receive lower recruitment than the mainland, and this is evident even on islands quite close to continental coasts (e.g. Crisp \& Southward 1958). The relatively small size and the strong currents that characterise oceanic island environments reduce larval retention (Swearer et al. 1999), resulting in a greater larval loss and, hence, lower recruitment. Thus, in these highly dispersive insular habitats, a reduction in reproductive output as a consequence of the removal of mature animals is likely to render island populations more susceptible to exploitation than would be expected elsewhere (Roberts \& Hawkins 1999). In the Canary Islands, for instance, intense exploitation of rocky intertidal limpets led to a dramatic reduction in these populations as well as to the local extinction of Patella candei candei (Côrte-Real et al. 1996, Navarro et al. 2005).

In the Azores, littoral organisms (e.g. barnacles, seaweeds and limpets) have been exploited since the islands were first colonised in the 15th century. Arguably, one of the largest anthropogenic impacts on these shores has been the exploitation of patellid limpets (Hawkins et al. 2000), which are gathered for food at both commercial and recreational levels. The economic value of limpets rose steadily in the 1980s, leading to a dramatic increase in exploitation. However, the extent of exploitation differed among islands, being greatest in São Miguel (the largest and most developed island), and least in the islands of the western group (Flores and Corvo) (Table 1). The fishery reached its peak in 1984 with a harvest $97000 \mathrm{~kg}$, of which $94000 \mathrm{~kg}$ were collected on São Miguel alone (Santos et al. 1990). Such intense harvesting prompted a marked decline in the limpet populations on São Miguel (Martins et al. 1987, Santos et al. 1990, Hawkins et al. 2000), and the fishery collapsed in 1985. In 1993, legislation was passed to protect this resource. Limpet no-take areas were created, whereas a seasonal harvesting restriction from November to May was applied elsewhere in addition to minimum legal catch sizes of 30 and $50 \mathrm{~mm}$ shell length for Patella
Candei d'Orbigny, 1840 and P. aspera Röding, 1798, respectively. Ferraz et al. (2001) reported some limpet population recovery in 1998 in the western and central groups of islands, but not at São Miguel. Although informative, these studies did not consider limpet density, since they were based on captures per unit time (but see Hawkins et al. 1990). Preliminary work by the present authors indicates that limpet density, particularly that of $P$. aspera, has remained low throughout the archipelago and that the protective measures adopted by the government in 1993 have had little impact on the recovery of these populations.

Hence, limpets are used as a model species in this work, as they represent an economically important resource and because they are considered key organisms whose role in structuring the rocky intertidal is widely recognised. For instance, experimental evidence has shown that limpets, and particularly patellid limpets in the NE Atlantic, have a strong top-down influence on the structure of the rocky intertidal (e.g. Hawkins et al. 1992, Coleman et al. 2006), suggesting that a reduction in limpet abundance as a consequence of over-exploitation is likely to have strong community level effects through direct and indirect interactions (e.g. Van Tamelen 1987). In addition, whilst most experimental work has been done at small spatial scales (e.g. quadrats), differences in the exploitation regime among islands may allow us to examine the impacts of harvesting at landscape scales.

The main purpose of the present study was to evaluate the limpet population structure across the Azores archipelago. We tested the proposition that the fragmented and isolated nature of these islands makes it possible to examine the impact of different exploitation regimes as a function of each island's fishing history. We hypothesised a decrease in both limpet density and maximum size toward the eastern islands, reflecting greater fishing effort. We also examined the potential effects that grazer exploitation may have on the structure of mid-shore assemblages. 


\section{MATERIALS AND METHODS}

Study sites and community. The Azorean archipelago comprises 9 volcanic islands organised in 3 separate groups (eastern, central and western), and is located between the coordinates 37 to $40^{\circ} \mathrm{N}, 25$ to $31^{\circ} \mathrm{W}$. The islands are surrounded by deep water, and the coastline topography is complex, with steep cliffs alternating with rocky shores. Sandy beaches are rare. The present study considered 4 islands spanned across the archipelago (Flores, Graciosa, Pico and São Miguel) that differed in the history of limpet exploitation (Table 1), and focused on the 2 patellid species present on these islands: Patella aspera and $P$. candei. The former is a slow-growing protandrous species that can attain large sizes (all individuals are male at $20 \mathrm{~mm}$ shell length, while $70 \%$ of mature animals at $55 \mathrm{~mm}$ are female; Thompson 1979). The latter is a faster growing, more opportunistic species. It is gonochoric and attains maximal sizes smaller than $P$. aspera (Martins et al. 1987).

The present study was done on moderately exposed rocky shores and at mid-tidal heights $(1.90 \pm 0.1 \mathrm{~m}$ above Chart Datum), where populations of Patella spp. attain maximal densities (Hawkins et al. 1990, Martins et al. 2008). At these heights, assemblages are generally represented by a patchy distribution of coarsely branched algae (e.g. Gelidium microdon Kützing, Osmundea spp.), the barnacle Chthamalus stellatus (Poli) and bare rock, patellid limpets being the most abundant grazers (Hawkins et al. 1990, Martins et al. 2008).

Sampling design. Field work was conducted during the summer of 2006. On each of the 4 islands, 3 locations were selected, and, at each of these, 3 sites comprising a $30 \mathrm{~m}$ stretch of the shore were chosen. Locations were selected at random but with the proviso that they had similar environmental conditions (e.g. slope, exposure to wave action). At each site, limpets were counted within 5 replicate $25 \times 25 \mathrm{~cm}^{2}$ quadrats, and their abundance was expressed as the number of individuals per quadrat. All limpets within replicate quadrats were measured to the nearest millimetre using Vernier callipers. The biomass of Patella candei was estimated using a previously calculated relationship between biomass and shell length (biomass $[\mathrm{g}]=0.0001 \times$ shell length $[\mathrm{mm}]^{2.79}, \mathrm{r}^{2}=0.96 ;$ G. M. Martins unpubl. data). The biomass of $P$. aspera was not considered, as there were insufficient animals from which a robust relationship could be estimated. Quadrats were photographed to assess percentage cover of key morphological groups (erect algae and barnacles) by overlaying 50 random points on each photograph and recording the organism beneath, thus defining the assemblage of space-occupiers. Lack of abundant and large canopy algae (e.g. fucoids) allowed this approach to accurately determine percentage cover of major space occupiers.

Data analysis. Two approaches were used to test the general hypothesis that the population structure of limpets differs among islands. The abundance and biomass of limpets were analysed using a 3-way mixedmodel analysis of variance (ANOVA), with the following factors: island (fixed factor, 4 levels), location (random factor, 3 levels, nested within island) and site (random factor, 3 levels, nested within location and island), with 5 replicates. Prior to analysis, data were checked for heterogeneity of variances using Cochran's test and transformations were applied where necessary following Underwood (1997). In one particular case (density of Patella aspera, see Table 2), transformations were unsuccessful in removing heterogeneity. However, ANOVA is relatively robust to heterogeneous variances in large designs (Underwood 1997) and, hence, untransformed data were analysed. Student-Newman-Keuls (SNK) tests were used to compare means within significant factors. In addition, the chi-squared test of association was used to test the null hypothesis of no association between the frequency of $P$. candei (there were not sufficient data for the analysis of $P$. aspera) in different size classes and at different islands. Visual analyses were made using $5 \mathrm{~mm}$ size classes (see Fig. 2), which corresponds to half the shell length that $P$. candei is able to attain in its first year (Menezes 1991). However, data had to be grouped in $10 \mathrm{~mm}$ size classes for the chi-squared analysis, in order to reduce the number of zeros and the number of cells with $<5$ observations (Quinn \& Keough 2002). In this analysis, the 6 animals that were $>30 \mathrm{~mm}$ were lumped together in the largest size class $(>20 \mathrm{~mm})$.

In order to examine if differences among islands could be attributed to the islands' regime of exploitation, the total number of Patella candei and the number of larger individuals $(>20 \mathrm{~mm})$ at each island were regressed against catch rates (see Table 1). However, since data from landings are potentially underestimated (e.g. does not include illegal harvesting), data were also regressed against the number of islanders per coastal perimeter. This index provides an indirect estimate of potential exploitation in each island.

The role of patellid limpets in structuring the rocky intertidal in the NE Atlantic is well documented (see 'Introduction'). To test the hypothesis that changes in the abundance of limpets may lead to changes in the dominance of mid-shore assemblages between macroalgae and barnacles, we used both ANOVA and correlation analyses. ANOVAs were used as above to test for differences in the abundance of algae and barnacles among islands. Since there is no experimental evidence of the direct or indirect effect of limpets on 
the community structure in the Azores, correlations were used to examine the relationship between the abundance of limpets and the abundance of macroalgae and barnacles. Probabilities were adjusted by Bonferroni correction. Finally, in order to examine if differences in the abundance of limpets among islands can lead to changes in the structure of mid-shore assemblages at landscape scales, the mean limpet abundance at each island was correlated with the mean cover of algae and barnacles, respectively.

\section{RESULTS}

\section{Population level effects}

The 2 species of limpets, Patella candei and $P$. aspera, differed greatly in abundance and distribution. The former was common in the rocky intertidal of all islands, whilst $P$. aspera was restricted to a few individuals at Flores, being nearly absent at the remaining islands.

Although the hypothesis that the abundance of Patella candei differs among islands was rejected (Table 2), it was very close to significance ( $p=0.0521)$. This and the fact that a large proportion of the overall variability was indeed associated with the scale of islands (analysis of the components of variation; not shown) suggests that a significant test for islands may have been masked by the low power of this test (see degrees of freedom in Table 2) and by the significant effect among locations-the denominator of the F-test for islands. Despite this, there was significant variation in the biomass of $P$. candei among islands (Fig. 1, Table 2). SNK tests showed a significantly higher biomass of $P$. candei at Flores (mean \pm SE: $1.75 \pm 0.25$ ) than at the remaining 3 islands, among which there was no variation, ranging between $0.28 \pm 0.06$ at Graciosa, $0.42 \pm 0.07$ at São Miguel and $0.74 \pm 0.13 \mathrm{~g}$ quadrat $^{-1}$ at Pico (Fig. 1). There was significant variation in the abundance of $P$. aspera among islands: at Flores, it attained mean $( \pm \mathrm{SE})$ densities of $0.4 \pm 0.1$, whilst it was virtually absent at the remainder of the 3 islands (Fig. 1, Table 2).

There was small-scale, intra-island variation for both the abundance and biomass of Patella candei (Fig. 1, Table 2). This probably reflects natural variability in recruitment. However, it could also be the result of spatial variation in the intensity of limpet exploitation within islands. At present, no data are available that would allow us to ascertain the causes of this variability, and, since these were considered random factors, this variation is not discussed further.

Analysis of the frequency of limpets in each size class (Fig. 2) showed a normal distribution, with a modal size class of 10 to $15 \mathrm{~mm}$ at 3 of the islands. It should be noted that at all islands, out of 487 limpets recorded, only 6 were found to be larger than the legal catch size $(30 \mathrm{~mm})$ and of these 5 were recorded at Flores. A significant association was detected between the frequency of limpets in each size class and islands $\left(\chi^{2}=\right.$ $35.98, \mathrm{df}=6, \mathrm{p}<0.001)$. Inspection of the relative chisquared values (Table 3 ) shows important contributors to this pattern were a greater number of large limpets at Graciosa than expected and a lower number at São Miguel. To a lesser extent, there were also fewer small limpets $(<10 \mathrm{~mm})$ at Graciosa than would be expected.

The number of islanders per coastal perimeter was a better predictor of the abundance of Patella candei across the archipelago than the level of limpet catches. The number of larger animals decreased with increasing island population (Fig. 3), whilst no correlation was found with the catch data $\left(F_{1,2}=4,71, \mathrm{R}^{2}=0.70, \mathrm{p}>\right.$ $0.16)$. However, the total number of limpets per island (including animals of all sizes) did not correlate with either the island population $\left(F_{1,2}=0.41, \mathrm{R}^{2}=0.17, \mathrm{p}>\right.$ $0.58)$ or the catch data $\left(F_{1,2}=0.004, \mathrm{R}^{2}<0.01, \mathrm{p}>0.95\right)$.

\section{Community level effects}

There was significant variation in the abundance of algae at the scale of islands and sites (Table 4). At the larger scale of islands, the percentage cover of algae

Table 2. Patterns of limpet abundance and biomass at a hierarchy of spatial scales: Island (Is, fixed), Location (Lo, random and nested within islands) and Site ( $\mathrm{Si}$, random and nested within locations and islands)

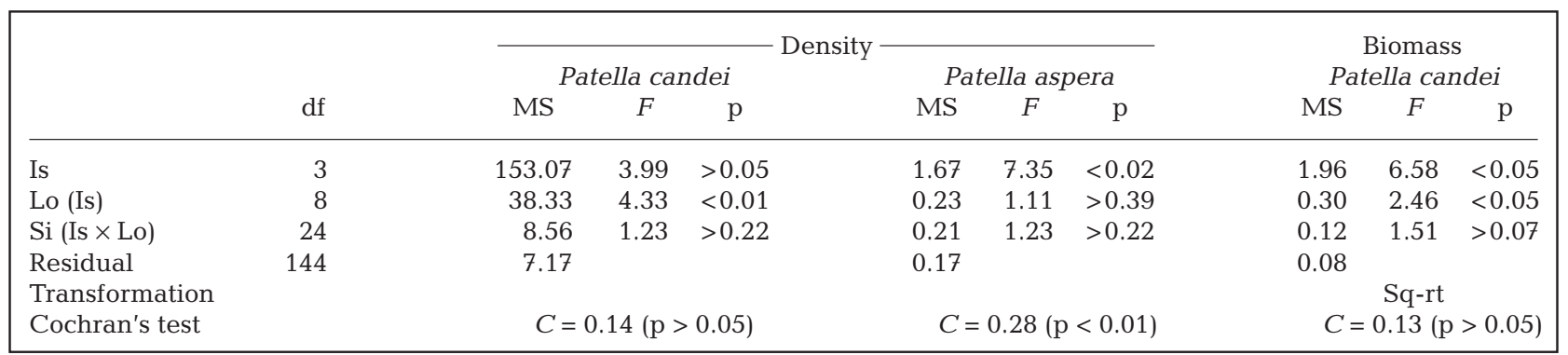



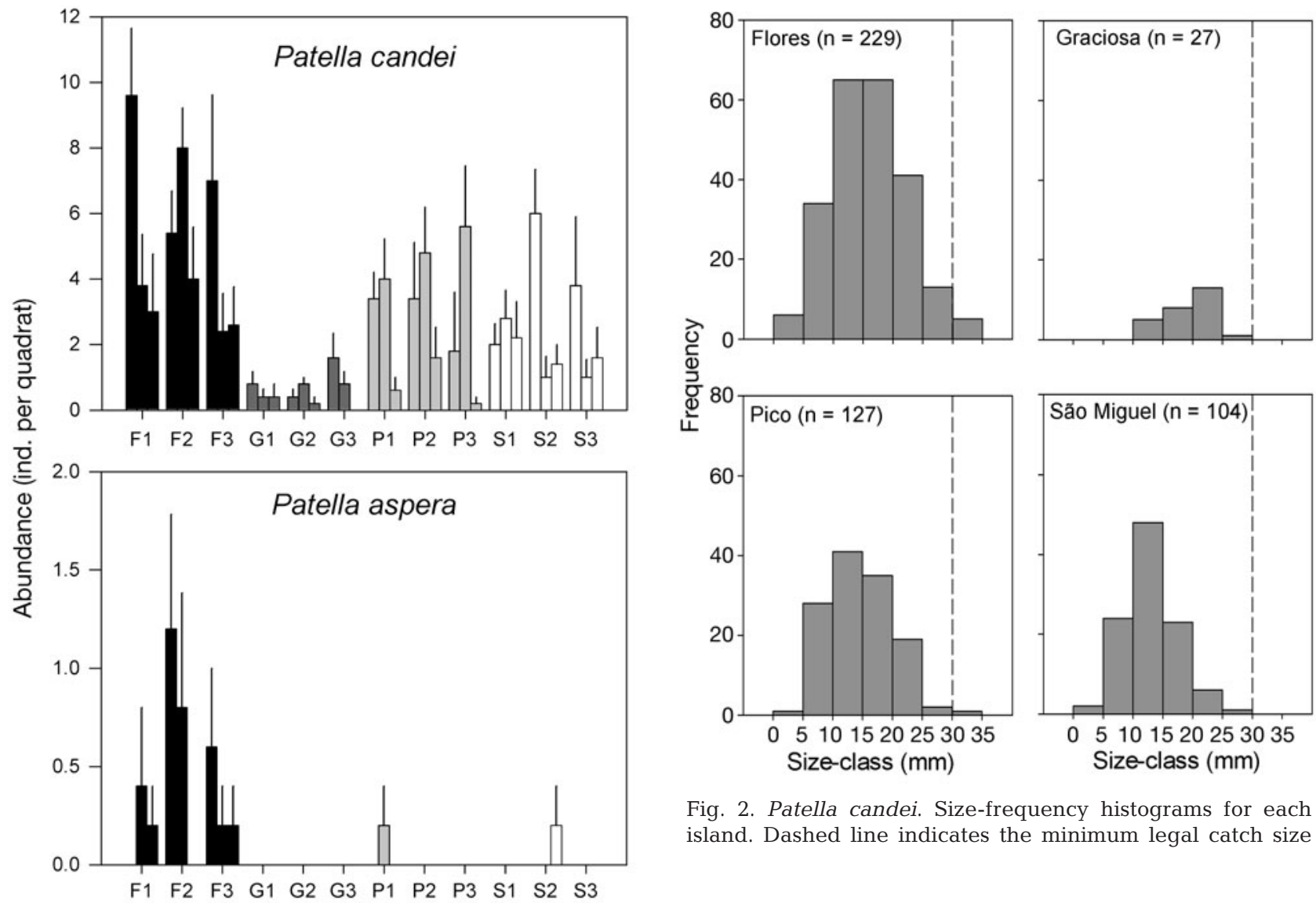

Fig. 2. Patella candei. Size-frequency histograms for each island. Dashed line indicates the minimum legal catch size

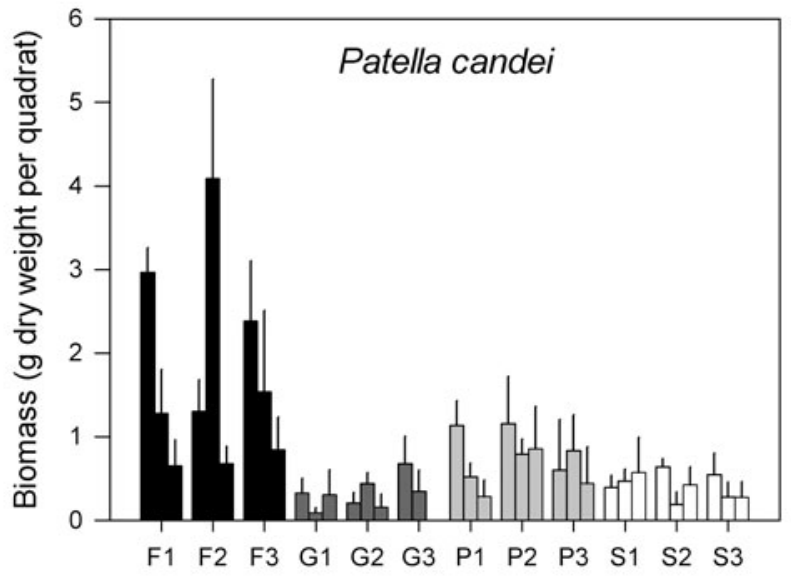

Fig. 1. Patella spp. Mean (+SE) limpet abundance and biomass. Each bar represents 1 site on each shore. Flores-F1: Fajã Grande, F2: Lajedo, F3: Fajãzinha; Graciosa-G1: Porto Afonso, G2: Santa Cruz, G3: Carapacho; Pico-P1: Prainha, P2: Lajes, P3: Santa Cruz; São Miguel-S1: Lagoa, S2: Caloura, S3: Mosteiros

(mean $\pm \mathrm{SE}$ ) ranged between $25.9 \pm 3.7$ at Flores and $56.3 \pm 4.1$ at São Miguel (Fig. 4). A similar pattern of distribution was observed for barnacles, with significant variation at the largest and smallest scales (Table 4). The abundance of barnacles (mean percent-

Table 3. Patella candei. $\chi^{2}$ test of association between the frequency of limpets at different size-classes and islands

\begin{tabular}{|lcccc|}
\hline & Flores & Graciosa & Pico & São Miguel \\
\hline $\mathbf{0 - 1 0} \mathbf{~ m m}$ & & & & \\
Observed & 40 & 0 & 29 & 26 \\
Expected & 44.7 & 5.3 & 24.8 & 20.3 \\
$\chi^{2}$ contribution & 0.5 & 5.3 & 0.7 & 1.6 \\
$\mathbf{1 1 - 2 0} \mathbf{~ m m}$ & & & & \\
Observed & 130 & 13 & 76 & 71 \\
Expected & 136.4 & 16.1 & 75.6 & 61.9 \\
$\chi^{2}$ contribution & 0.3 & 0.6 & $<0.1$ & 1.3 \\
$>\mathbf{2 0}$ mm & & & & \\
Observed & 59 & 14 & 22 & 7 \\
Expected & 48.0 & 5.7 & 26.6 & 21.8 \\
$\chi^{2}$ contribution & 2.5 & 12.3 & 0.8 & 10.0 \\
\hline
\end{tabular}

age cover \pm SE) was greatest at Flores $(35.9 \pm 2.6)$ and lowest at São Miguel $(15.5 \pm 2.0)$, whereas intermediate levels were recorded for Pico and Graciosa $(26.3 \pm 2.3$ and $23.1 \pm 2.4$, respectively; Fig. 4). As with limpets (see previous subsection), significant variation at the smaller scale of sites among algae and barnacles is probably the result of natural variability (i.e. recruitment, competition for space). 


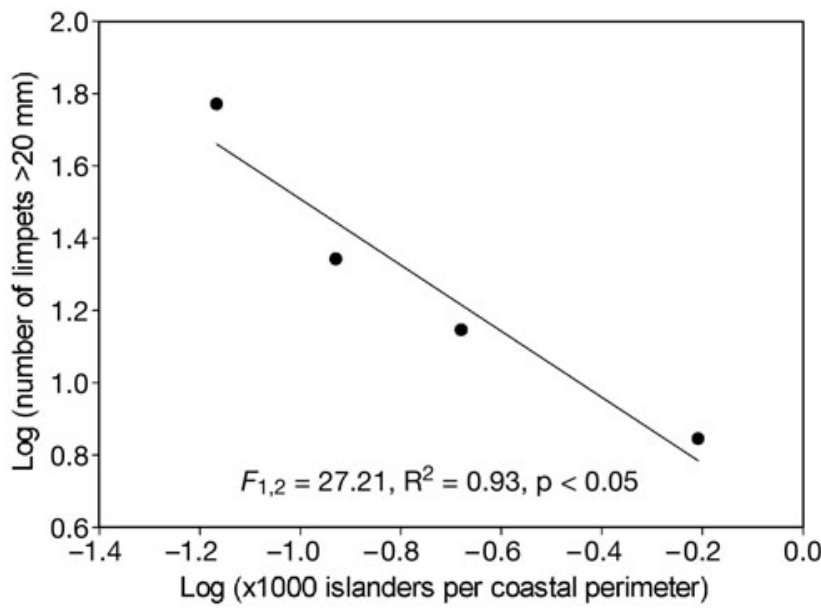

Fig. 3. Patella candei. Regression analysis between the number of limpets $>20 \mathrm{~mm}$ (shell length) and the number of islanders per coastal perimeter at each island

There was a significant negative correlation between the abundance of limpets and the percent cover of algae $\left(F_{1,178}=10.88, \mathrm{R}=0.24, \mathrm{p}<0.01\right)$, although the correlation coefficient was weak. In contrast, a clearer relationship was detected between the maximum cover of algae and the density of limpets (Fig. 5). Similarly, whilst barnacle cover was weakly correlated with limpet density $\left(F_{1,178}=19.51, \mathrm{R}=0.31\right.$, $\mathrm{p}<0.001$ ), there was a strong positive correlation between the density of limpets and minimum cover of barnacles (Fig. 5). In addition, the percent cover of barnacles was inversely correlated with the cover of algae $\left(F_{1,178}=239.26, \mathrm{R}=0.76, \mathrm{p}<0.001\right)$. This 3 -way relationship between limpets, algae and barnacles differed among islands and would likely have consequences for mid-shore community structure, as islands supporting a greater abundance of limpets (e.g. Flores) tended to support mid-shore assemblages with greater abundance of barnacles. In contrast, at lower abundances of limpets (e.g. São Miguel), islands tended to support algal-dominated mid-shore assemblages (Fig. 6).

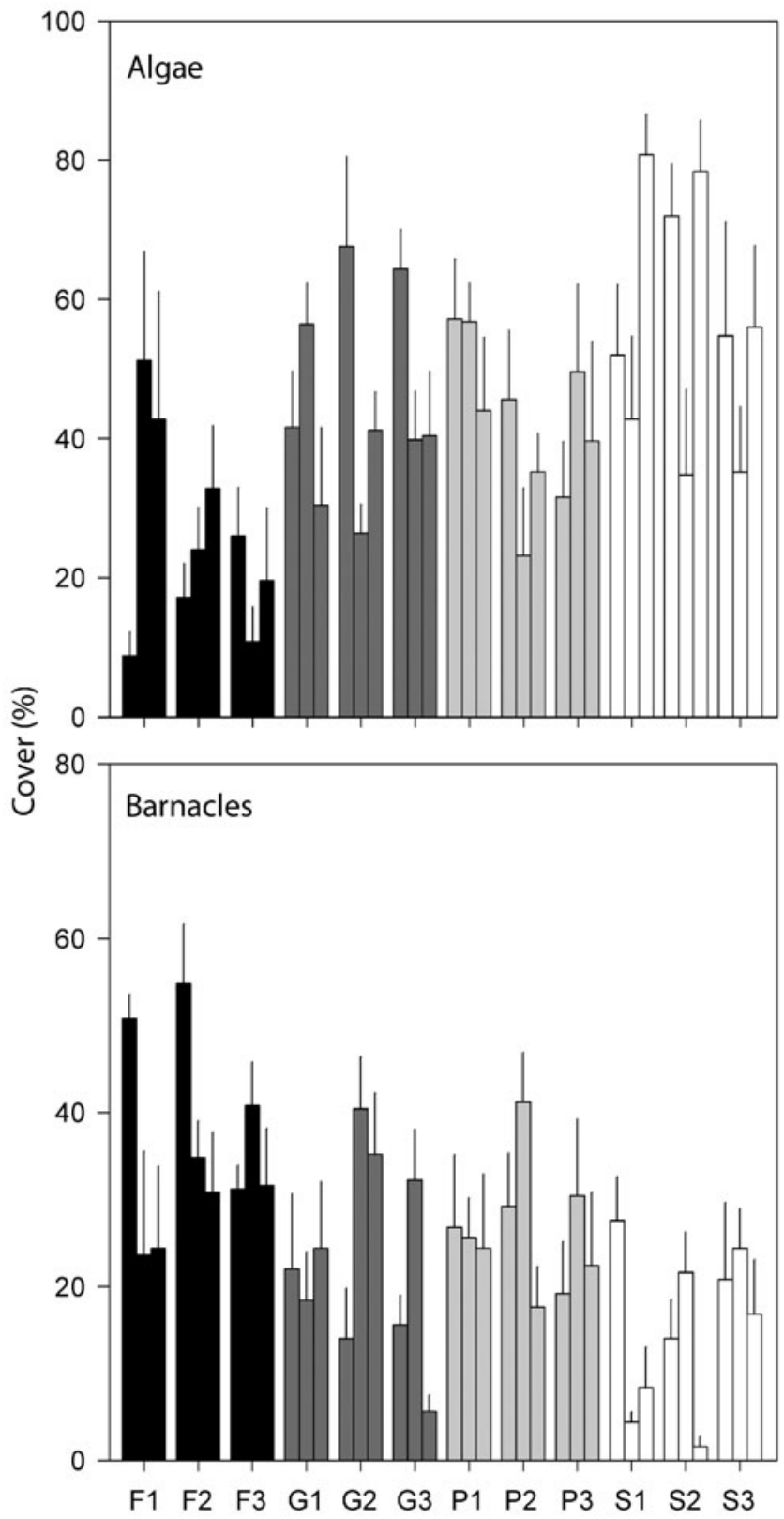

Fig. 4. Mean (+SE) algal and barnacle cover. Site abbreviations as in Fig. 1

\section{DISCUSSION}

The idea that the sea offers an infinite supply of resources and that humanity could not cause the extinction of marine species is slowly changing (Roberts \& Hawkins 1999), and there is growing evidence that, as well as affecting target species, fishing can have a wider influence, through cascading trophic effects (Castilla 1999, Scheffer et al. 2005).
Table 4. Patterns of algal and barnacle abundance at a hierarchy of spatial scales. See Table 2 for nomenclature

\begin{tabular}{|lccccccc|}
\hline & df & \multicolumn{3}{c}{ Algal cover } & \multicolumn{4}{c|}{ Barnacle cover } \\
& & MS & $F$ & p & MS & $F$ & p \\
\hline Is & 3 & 57.13 & 5.53 & $<0.05$ & 3200 & 4.56 & $<0.05$ \\
Lo (Is) & 8 & 10.33 & 1.77 & $>0.13$ & 700 & 1.79 & $>0.12$ \\
Si (Lo $\times$ Is) & 24 & 5.83 & 1.72 & $<0.05$ & 390 & 1.97 & $<0.01$ \\
Residual & 144 & 3.40 & & & 190 & & \\
Transformation & \multicolumn{3}{|c|}{ Sq-rt } & & & \\
Cochran's test & \multicolumn{3}{c}{$C=0.08(\mathrm{p}>0.05)$} & & $C=0.10(\mathrm{p}>0.05)$ \\
\hline
\end{tabular}




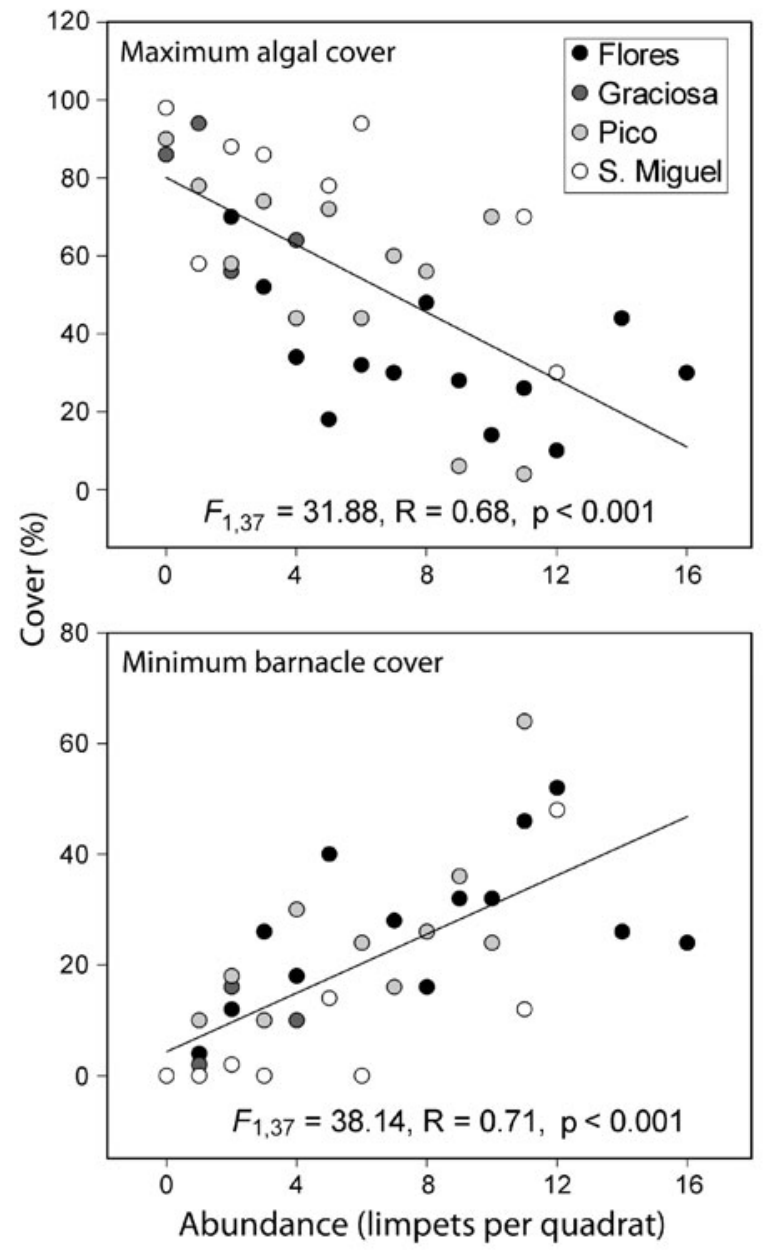

Fig. 5. Correlations between the abundance of limpets and the maximum and minimum percentage cover of algae and barnacles, respectively

The present study provides a thorough analysis of the abundance of exploited species in a seldomstudied system. The 2 species of limpets examined differed greatly in distribution and abundance. Patella candei occurred on all islands in relatively large numbers, whilst populations of $P$. aspera were small and virtually absent at 3 out of the 4 islands examined. Both species co-occur in the intertidal, where their density is maximal at mid-shore levels (Hawkins et al. 1990, Martins et al. 2008). Differences in the abundance between the 2 species could be the result of natural processes such as inter-specific competition (Boaventura et al. 2002). However, it is unlikely that natural processes alone could have caused the absence of $P$. aspera at 3 islands. Instead, a much more likely explanation is that the low abundance of $P$. aspera is a consequence of intense exploitation. Unfortunately, catch data combine the 2 species together, and it is impossible to determine the fishing effort for each species separately. However, anecdotal evidence suggests that

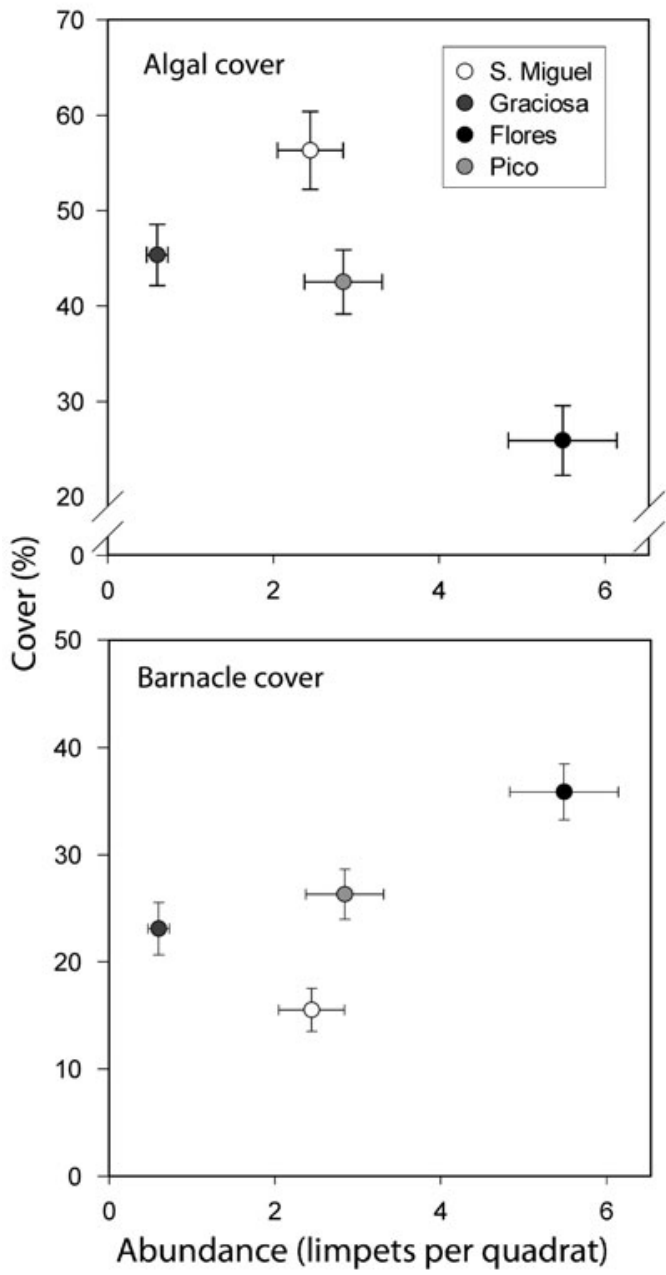

Fig. 6. Graphical representation of mid-shore assemblage structure of the 4 islands considered in the present study

P. aspera was harvested in much greater numbers than $P$. candei, probably because the former attains greater maximum sizes. In addition, the biology of $P$. aspera (see 'Materials and methods') renders it more susceptible to exploitation than P. candei (Martins et al. 1987, Roberts \& Hawkins 1999), which is likely to amplify the difference in the abundance between the 2 species.

As hypothesised, the population structure of limpets differed among islands. However, catch data (Table 2) failed to provide a comprehensive explanation of such variation. These data are based on the logbook records of licensed harvesters. There is, however, much illegal harvesting at these islands (G. M. Martins pers. obs.), and limpets are commonly sold directly to restaurants or on the streets without being declared. In addition, as the abundance of larger animals becomes scarcer (see Fig. 2), harvesters tend to collect smaller animals below the legal size, and these are obviously not declared. Hence, a large number of animals are not included in official statistics, and catch data fail to represent actual 
rates of exploitation. The number of islanders per coastal perimeter proved a much more reliable index in predicting the variation in the abundance of limpets among islands and especially that of the larger animals. Similar indexes (e.g. number of fishing boats per island) have been successfully used in other archipelagos (Tuya et al. 2006), suggesting that they can provide adequate information for the management of fisheries in fragmented habitats. A similar approach has also been used in mainland coastal areas, where the intensity of exploitation was driven by the distance to populated centres (e.g. Rius et al. 2006). The drawback of using such correlative approaches is that causality cannot be inferred from results. As such, differences in the population structure of limpets among islands cannot be ascribed to exploitation alone, since these islands may differ in relation to factors other than fishing intensity (e.g. competition, productivity, mortality). Hence, interpretation of results should be done with caution and considering the biology and ecology of the species involved. The use of such indexes and consequent correlative approach may, however, be the only possible way to ascertain the effects of exploitation in areas where suitable control areas (e.g. no-take marine reserves) are lacking.

In the present study, the population structure of Patella candei shows clear evidence of intense exploitation. Few animals were recorded with shell lengths greater than the minimum legal catch size, and there was a clear reduction in the abundance of larger animals across the gradient of exploitation. Despite this, limpet numbers seemed to be relatively stable across the archipelago. Martins et al. (1987) argue that the biology of $P$. candei may render this species susceptible to size exploitation (a reduction in size), but not recruitment exploitation (a reduction in abundance). However, in the Canary Islands, the populations of $P$. candei crashed due to over-exploitation (Côrte-Real et al. 1996, Navarro et al. 2005). This suggests that even opportunistic species such as $P$. candei may be susceptible to population disruption under intense exploitation. It should be noted that, as an endemic species to the Macaronesian Islands, P. candei is self-recruiting and hence more vulnerable to local reduction in reproductive output. The alarmingly low number of limpets in Graciosa, especially in the smaller size classes (see Fig. 2) may be evidence of such a crash. Graciosa is the smallest $(23 \mathrm{~km}$ of coastal perimeter) and most northerly island of those in the central group. Since the predominant currents in the Azores are from the NW (Morton et al. 1998), this may mean that Graciosa receives little supply of larvae from the other islands. The low numbers of animals found in Graciosa could therefore be the result of recruitment exploitation.
Removal of particular species may lead to changes in assemblage composition and structure in a variety of marine environments (e.g. Farrell 1988, BenedettiCecchi \& Cinelli 1992). These changes can be predicted to a certain extent, depending on the identity of the species lost. Experimental work on the importance of top-down control of algae by intertidal limpets (e.g. Underwood 1984, Hawkins et al. 1992, Coleman et al. 2006) clearly suggests that patellid exploitation is likely to have a strong impact on community structure. The correlative approach used here showed a clear decrease in algal cover with increasing limpet abundance, which conforms to the wider literature. For instance, in Chile, human exclusion from the rocky intertidal areas resulted in an increase of fissurelid limpets and a concomitant decrease of algae (e.g. Moreno et al. 1984). In addition, there was a positive relationship between the abundance of limpets and barnacle cover. Limpets are known to affect the abundance and survival of barnacles directly, by killing or knocking small barnacles off the substratum (bulldozing), and, indirectly, by preventing barnacle overgrowth by algae (e.g. Denley \& Underwood 1979). As such, our results conform to the wider literature indicating that the importance of limpets in structuring the rocky intertidal does not differ between insular and continental habitats. However, our study differs from others by providing evidence of the role of humans as top-predators (see Siegfried 1994 for references) at landscape scales. This suggests that fragmented habitats (in general) and islands (in particular) can be good model systems to broaden the generality of other studies (Hewitt et al. 2007), although the results should be validated whenever possible, for instance by using suitable control areas (e.g. no-take marine reserves).

In the present study, it was not possible to ascertain the specific role of each species (Patella candei or $P$. aspera) in controlling algae in the Azores. Patellid species can differ significantly in the effectiveness in which they control macroalgae. For example, Moore et al. (2007) showed that $P$. vulgata was a more effective grazer than $P$. depressa in southwest Britain, although in Portugal both species had similar strengths (Boaventura et al. 2002). In the Azores, there is no evidence to conclude that the 2 species of limpets differ in terms of diet, and future studies should therefore examine this. However, considering the overall scarcity of $P$. aspera in the archipelago, it is most likely that $P$. candei is, at present, the most important grazer of the Azores rocky intertidal.

The effects of human activities on biological systems are complex (Lindberg et al. 1998), and it becomes increasingly difficult to predict the wider effects of exploitation at higher trophic levels. Islands commonly support assemblages that are less diverse than those 
observed in the corresponding continental habitat. Over-exploitation could have irreversible impacts such as the local extinction of target species and a substantial decrease in - or even a total elimination of - the ecosystem function provided by the exploited species. In a more extreme scenario, it could lead to the disruption of a system by altering the food chain length.

The present study provides a thorough characterisation of the population structure of limpets across the Azores. It assessed the current status of these populations, providing good background data against which future studies can be compared. Results suggest that differences among islands are probably related to the islands' history of exploitation, although the fact that suitable no-take marine reserve data are not available prevents causality from being determined. Our study is of particular interest, since the fragmented nature of island habitats allowed us to examine the role of limpets in structuring the rocky intertidal at landscape scales.

Acknowledgements. The authors are grateful to Secretaria Regional dos Equipamentos e Transportes (SRET) and Câmara Municipal of Santa Cruz da Graciosa for, respectively, transport and accommodation at that island. G.M.M. is personally grateful to $\mathrm{M}$. A. Cabral for help during the field trip to Flores. This work was supported by Postgraduate Grant SFRH/BD/22009/2005 awarded to G.M.M. by Fundação para a Ciência e Tecnologia (FCT). S.R.J. and S.J.H. were supported by NERC grants to the Marine Biological Association of the UK. Thanks are due to J.M.N. Azevedo and 2 anonymous referees for improving the manuscript.

\section{LITERATURE CITED}

Benedetti-Cecchi L, Cinelli F (1992) Effects of canopy cover, herbivores and substratum type on patterns of Cystoseira spp. settlement and recruitment in littoral rockpools. Mar Ecol Prog Ser 90:183-191

> Boaventura D, Fonseca LC, Hawkins SJ (2002) Analysis of competitive interactions between the limpets Patella depressa Pennant and Patella vulgata L. on the northern coast of Portugal. J Exp Mar Biol Ecol 271:171-188

Branch GM (1975) Notes on the ecology of Patella concolor and Cellana capensis, and the effects of human consumption on limpet populations. Zool Afr 10:75-85

> Caley MJ, Carr MH, Hixon MA, Hughes TP, Jones GP, Menge BA (1996) Recruitment and the local dynamics of open marine populations. Annu Rev Ecol Syst 27:477-500

Castilla JC (1999) Coastal marine communities: trends and perspectives from human-exclusion experiments. Trends Ecol Evol 14:280-283

Castilla RC, Durán LR (1985) Human exclusion from the rocky intertidal zone of central Chile: the effects on Concholepas concholepas (Gastropoda). Oikos 45:391-399

> Coleman RA, Underwood AJ, Benedetti-Cecchi L, Åberg P and others (2006) A continental scale evaluation of the role of limpet grazing on rocky shores. Oecologia 147:556-564

Côrte-Real HB, Hawkins SJ, Thorpe JP (1996) Population differentiation and taxonomic status of the exploited limpet Patella candei in the Macaronesian islands (Azores,
Madeira, Canaries). Mar Biol 125:141-152

Crisp DJ, Southward AJ (1958) The distribution of intertidal organisms along the coasts of the English Channel. J Mar Biol Assoc UK 37:157-208

Denley EJ, Underwood AJ (1979) Experiments on factors influencing settlement, survival, and growth of 2 species of barnacles in New South Wales. J Exp Mar Biol Ecol 36:269-293

Durán LR, Castilla JC (1989) Variation and persistence of the middle rocky intertidal community of central Chile, with and without human harvesting. Mar Biol 103:555-562

> Farrell TM (1988) Community stability: effects of limpet removal and reintroduction in a rocky intertidal community. Oecologia 75:190-197

Ferraz RR, Menezes GM, Santos RS (2001) Limpet (Patella spp.) (Mollusca: Gastropoda) exploitation in the Azores, during the period 1993-1998. Arquipel Bull Univ Azores Life Mar Sci Part B (Suppl 2):59-65

Hawkins SJ, Burnay LP, Neto AI, Tristão da Cunha R, Martins AMF (1990) A description of the zonation patterns of molluscs and other important biota on the south coast of São Miguel, Azores. Açoreana (Suppl):21-38

Hawkins SJ, Hartnoll RG, Kain JM, Norton TA (1992) Plant-animal interactions on hard substrata in the NorthEast Atlantic. In: John DM, Hawkins SJ, Price JH (eds) Plant-animal interactions in the marine benthos. Clarendon Press, Oxford

Hawkins SJ, Côrte-Real HBSM, Pannacciulli FG, Weber LC, Bishop JDD (2000) Thoughts on the ecology and evolution of the intertidal biota of the Azores and other Atlantic islands. Hydrobiologia 440:3-17

> Hewitt JE, Thrush SF, Dayton PK, Bonsdorff E (2007) The effect of temporal and spatial heterogeneity on the design and analysis of empirical studies of scale-dependent systems. Am Nat 169:398-408

Lindberg DR, Estes JA, Warheit KI (1998) Human influences on trophic cascades along rocky shores. Ecol Appl 8: $880-890$

Martins HR, Santos RS, Hawkins SJ (1987) Exploitation of limpets (Patella spp.) in the Azores with a preliminary analysis of the stocks. ICES CM 1987/K:53:1-18

Martins GM, Thompson RC, Hawkins SJ, Neto AI, Jenkins SR (2008) Rocky intertidal community structure in oceanic islands: scales of spatial variability. Mar Ecol Prog Ser 356: $15-24$

Menezes GM (1991) Aspectos da biologia e ecologia de Patella ulyssiponensis aspera e P. candei candei (Mollusca, Gastropoda, Patellidade) dos Açores. Potencial da sua exploração. Tese de Licenciatura, Univesidade de Lisboa, Lisbon

Minchinton TE, Scheibling RE (1993) Free space availability and larval substratum selection as determinants of barnacle population structure in a developing rocky intertidal community. Mar Ecol Prog Ser 95:233-244

> Moore P, Thompson RC, Hawkins SJ (2007) Effects of grazer identity on the probability of escapes by a canopy-forming macroalga. J Exp Mar Biol Ecol 344:170-180

Moreno CA, Sutherland JP, Jara HF (1984) Man as a predator in the intertidal zone of southern Chile. Oikos 42:155-160

Morgan S (2001) The larval ecology of marine communities. In: Bertness M, Gaines S, Hay M (eds) Marine community ecology. Sinauer Associates, Sunderland, MA

Morton B, Britton JC, Martins AMF (1998) Coastal ecology of the Azores. Sociedade Afonso Chaves, Ponta Delgada

Navarro PG, Ramírez R, Tuya F, Fernandez-Gil C, SanchezJerez P, Haroun RJ (2005) Hierarchical analysis of spatial distribution patterns of patellid limpets in the Canary 
Islands. J Molluscan Stud 71:67-73

Quinn GP, Keough MJ (2002) Experimental design and data analysis for biologists. Cambridge University Press, Cambridge

Rius M, Kaehler S, McQuaid CD (2006) The relationship between human exploitation pressure and condition of mussel populations along the south coast of South Africa. S Afr J Sci 102:130-136

Roberts CM, Hawkins JP (1999) Extinction risk in the sea. Trends Ecol Evol 14:241-246

Santos RS, Martins HR, Hawkins SJ (1990) Relatório de estudos sobre o estado das populações de lapas do Arquipélago dos Açores e da ilha da Madeira. Relatório da X Semana das Pescas dos Açores. Universidade dos Açores, Horta

Scheffer M, Carpenter S, Young B (2005) Cascading effects of overfishing marine systems. Trends Ecol Evol 20:579-581

Siegfried WR (1994) Rocky shores: exploitation in Chile and South Africa. Springer-Verlag, Heidelberg

Swearer SE, Caselle JE, Lea DW, Warner RR (1999) Larval retention and recruitment in an island population of a coral-reef fish. Nature 402:799-802

Editorial responsibility: Erik Bonsdorf, Åbo, Finland and Karsten Reise, Sylt, Germany
Thompson GB (1979) Distribution and population dynamics of the limpet Patella aspera (Lamarck) in Bantry Bay. J Exp Mar Biol Ecol 40:115-135

> Thompson RC, Crowe TP, Hawkins SJ (2002) Rocky intertidal communities: past environmental changes, present status and predictions for the next 25 years. Environ Conserv 29:168-191

Thorson G (1950) Reproductive and larval ecology of marine bottom invertebrates. Biol Rev Camb Philos Soc 25:1-45

Tuya F, Sanchez-Jerez P, Haroun RJ (2006) Populations of inshore serranids across the Canarian Archipelago: relationships with human pressure and implications for conservation. Biol Conserv 128:13-24

> Underwood AJ (1984) Vertical and seasonal patterns in competition for microalgae between intertidal gastropods. Oecologia 64:211-222

Underwood AJ (1997) Experiments in ecology: their logical design and interpretation using analysis of variance. Cambridge University Press, Cambridge

Tamelen PG (1987) Early successional mechanisms in the rocky intertidal: the role of direct and indirect interactions. J Exp Mar Biol Ecol 112:39-48

Submitted: November 1, 2007; Accepted: April 11, 2008 Proofs received from author(s): June 17, 2008 